Fragrâncias Almiscaradas em Espectros Teóricos de IV por Métodos Quânticos Semi-Empíricos

\author{
Magalhães, D. R. B.;* Maia, E. R.
}

Rev. Virtual Quim., 2014, 6 (5), 1391-1407. Data de publicação na Web: 8 de outubro de 2014

\author{
http://www.uff.br/rvq
}

\title{
Musk Fragrances in IR Theoretical Spectra Through Semi-Empirical Quantum Methods
}

\begin{abstract}
In 1996 Luca Turin put together different levels of semi-empirical quantum methods to specifically model odorant molecules. Resulting infrared theoretical spectra informed different fragrance profiles. This article brings a collection of theoretical spectra, generated through the employment of traditional Hamiltonians NDDO/AM1, PM3 and PM6, for sixteen known musk molecules, which are the significant notes of perfumes and also express fixative activity. The results indicate for the first time in the literature which vibrational modes are possibly responsible for musk odor. This structure-odor relationship essay may guide the design of novel musks as well as helping to identify new natural musk molecules.
\end{abstract}

Keywords: Musk; semi-empirical quantum methods; infrared spectroscopy.

\section{Resumo}

Em 1996, Luca Turin reuniu diferentes métodos quânticos semi-empíricos para a específica modelagem de odorantes. Os espectros teóricos obtidos na região do infravermelho informaram os diferentes perfis das fragrâncias. Assim, este artigo apresenta uma coleção de espectros teóricos, gerados do emprego dos tradicionais Hamiltonianos NDDO/AM1, PM3 e PM6, para dezesseis consagradas moléculas almiscaradas, que compõem as notas de fundo das fragrâncias e apresentam atividade fixativa. Os resultados indicam pela primeira vez na literatura quais modos vibracionais são possivelmente responsáveis pelo odor almíscar. Tal estudo da relação estrutura-odor pode guiar a modelagem de novos almíscares, como também ajudar a identificar novos almíscares de ocorrência natural.

Palavras-chave: Almíscar; métodos quânticos semi-empíricos; espectroscopia no infravermelho.

\footnotetext{
* Universidade de Brasília, Laboratório de Estudos Estruturais Moleculares (LEEM), Instituto de Química, UnB, C.P. 4478, CEP 70904-970, Brasília-DF, Brasil.

Mdanielabazuchi@gmail.com

DOI: $\underline{10.5935 / 1984-6835.20140091}$
} 


\title{
Fragrâncias Almiscaradas em Espectros Teóricos de IV por Métodos Quânticos Semi-Empíricos
}

\author{
Daniela R. B. Magalhães, * Elaine R. Maia \\ Universidade de Brasília, Laboratório de Estudos Estruturais Moleculares (LEEM), Instituto de \\ Química, UnB, C.P. 4478, CEP 70904-970, Brasília-DF, Brasil. \\ *danielabazuchi@gmail.com
}

Recebido em 12 de maio de 2014. Aceito para publicação em 6 de outubro de 2014

\section{Introdução}

2. Parte experimental

\section{Resultados e discussão}

\subsection{Resultados preliminares}

3.2. Espectros teóricos

3.3. Comparação com os espectros gerados por CHYPRE

\section{Conclusão}

\section{Introdução}

Em química computacional, os métodos quânticos semi-empíricos (QSE) se valem da resolução aproximada da equação de Schrödinger, que descreve um sistema químico através dos postulados da mecânica quântica, para a obtenção de propriedades químicas, tais como calor de formação, geometrias moleculares, momentos de dipolo e espectros de transição eletrônica. Para tanto, a função de onda $\Psi$ passa a ser descrita como um conjunto de bases, e cada método o manipulará através da inserção de valores empíricos fundamentados em dados experimentais e de restrições matemáticas na busca da simplificação dos cálculos. Também o operador Hamiltoniano $(\hat{H})$, que quando aplicado à função de onda fornece a energia do sistema, é descrito de forma simplificada. Em compensação, cada método adiciona parâmetros ajustáveis ao conjunto de bases, para que as propriedades calculadas reproduzam os dados experimentais. ${ }^{1}$

Tal formalismo confere aos métodos QSE baixo custo computacional e alta velocidade na conclusão dos cálculos, e, em consequência, permite $o$ tratamento de sistemas com grande quantidade de átomos e de sistemas com núcleos pesados, além de predizer com acurácia propriedades eletrostáticas de moléculas. Por outro lado, algumas das limitações destes métodos compreendem inconsistências na descrição de energias de excitação e de metais de transição, na previsão das ligações hidrogênio e dos efeitos de dispersão e polarizabilidade, como também na impossibilidade da manipulação do conjunto de bases visando à melhoria dos resultados. ${ }^{1}$ 
De forma inédita, em 1996, ${ }^{2}$ uma coleção de métodos QSE foi empregada na descrição de espectroscopia capaz de predizer fragrâncias diferentes. A última revisão desta teoria vibracional propôs o mimetismo in silico do ambiente biológico no qual uma molécula odorante é reconhecida pela proteína do trato olfativo. Para tanto, a rotação do odorante é permitida dentro de seu espaço de confinamento, e dois níveis de teorias e métodos QSE são empregados na construção deste novo algoritmo, denominado CHYPRE. ${ }^{2}$ Naquele trabalho e para os cálculos das frequências dos modos vibracionais e os deslocamentos atômicos empregou-se o programa MOPAC ${ }^{3}$ com os parâmetros estabelecidos no Hamiltoniano MNDO 4 com o método PM3. ${ }^{5}$ Separadamente estabeleceram-se os cálculos das cargas atômicas parciais com o programa ZIndo $/ 1^{6} \mathrm{e}$ para ambos os cálculos trabalhou-se com o pacote de programas CaCHE Worksystems (Oxford Molecular). ${ }^{7}$ A espectroscopia assim pressuposta é correlata à técnica IETS (do inglês, Inelastic Electron Tunneling Spectroscopy), cujas frequências dos modos vibracionais se equivaleriam às geradas na espectroscopia na região do infravermelho (IV). ${ }^{8}$ Em artigo publicado em 2002 , no qual
Turin empregou a metodologia computacional descrita, concluiu-se que diversos compostos almiscarados apresentavam, em comum, três bandas proeminentes com $\pm 200 \mathrm{~cm}^{-1}$ de largura e centradas em 700, 1500 (ou 1750 para nitroalmíscares) e $2200 \mathrm{~cm}^{-1}$ (assinalado como estiramento de carbonila), havendo a presença de uma banda de menor intensidade em $1000 \mathrm{~cm}^{-1}$ e também com $\Delta \lambda= \pm 200 \mathrm{~cm}^{-1}$.

O presente artigo, ao empregar o Hamiltoniano Neglect of Diatomic Differential Overlap $\left(\mathrm{NDDO}^{10}\right)$ associado aos métodos $\mathrm{AM} 1{ }^{11}{ }^{11} \mathrm{PM}^{5}{ }^{5}$ e PM6, ${ }^{12}$ nos espectros de IV coletados, procurou verificar a exatidão das previsões dos modos normais de vibração frente aos espectros experimentais, para então identificar quais estiramentos ou deformações são possivelmente responsáveis pelo odor almiscarado. A elucidação de tais modos vibracionais, que são a razão primeira para a ocorrência das bandas num espectro, permaneceu omissa na literatura até o presente momento. Para tanto, dezesseis almíscares (Figura 1), dentre aqueles presentes nos estudos anteriores da teoria vibracional, ${ }^{9}$ foram modelados.

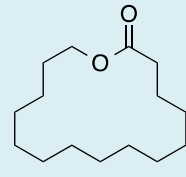

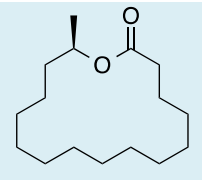

2

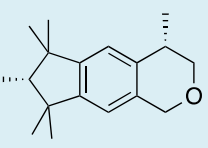

7

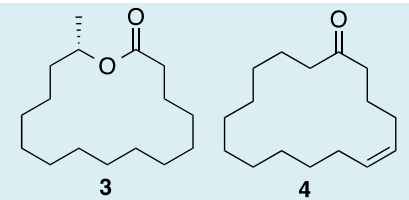

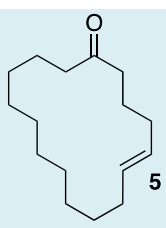

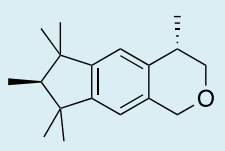

6

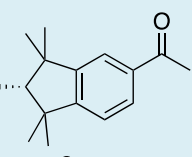

8

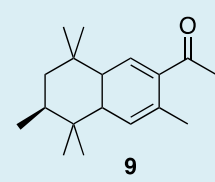

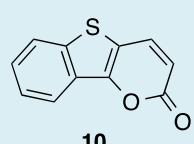

10

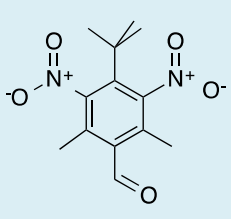

11

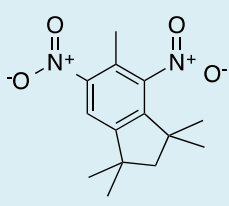

12

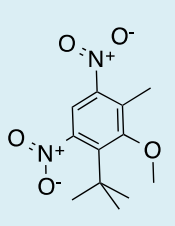

13
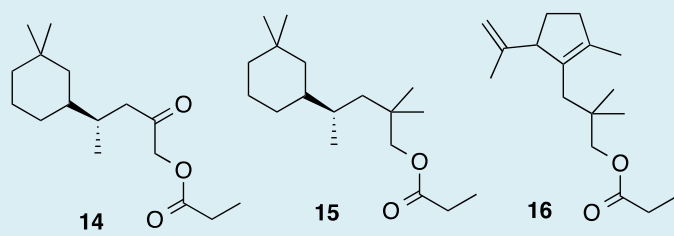

Figura 1. Base de dados dos almíscares em estudo: macrocíclicos: pentadecanolídeo (1), (R)exaltolídeo (2), (S)-exaltolídeo (3), cis-globanona (4) e trans-globanona (5); policíclicos: (4S,7S)-

galaxolídeo (6), (4S,7R)-galaxolídeo (7), indano (8), tetralina (9) e tonqueno (10); nitroalmíscares: almíscar cetona (11), almíscar mosqueno(12) e almíscar ambrete (13); acíclicos: helvetolídeo (14), romandolídeo (15) e (16) 
Por fim, outros horizontes se abrem com o estabelecimento desta relação estrutura odor. Primeiramente, torna-se possível o desenho racional de novos odorantes, o que diminui o esforço sintético dos processos de tentativa e erro. $O$ sucesso na geração de almíscares sintéticos é particularmente importante na atualidade, haja vista a proibição da utilização de produtos naturais de origem animal ${ }^{13}$ (tais como do veado almiscareiro, de cuja glândula anal de extraíam os almíscares $\left.1-3^{14,15}\right)$. Há também a possibilidade da identificação in silico de potenciais moléculas almiscaradas. Com a determinação de critérios estruturais que uma molécula deve apresentar para expressar o odor almíscar, será possível percorrer pelos exemplares de nossa flora brasileira na busca de compostos que satisfaçam tais condições requeridas. Isto pode ser feito, por exemplo, por triagem virtual inversa. ${ }^{16}$ As autoras pretendem seguir nesta pesquisa em breve.

\section{Parte experimental}

A construção das moléculas foi feita através das funcionalidades implementadas no programa Basic, da cadeia de programas Materials Studio, ${ }^{17}$ versão 4.4. A correção das geometrias iniciais dos odorantes foi efetuada através do programa para MM e DM, Discover 3.0,18,19 com a tradicional sequencia dos métodos Steepest Descent e Conjugate Gradient, com o algoritmo PolakRibiere, e convergência do gradiente a 1,0 $\mathrm{x}$ $10^{-4} \mathrm{kcal} \mathrm{mol}^{-1} \AA^{-1}$. O campo de força escolhido foi CFF99/Compass. ${ }^{20-22}$

As trajetórias de dinâmica foram conduzidas sob vácuo, à temperatura de 350 $\mathrm{K}$, e por tempo de $1,0 \mathrm{~ns}$, através do programa Discover 3.0. ${ }^{18,19}$ Utilizou-se o ensemble canônico NVT. ${ }^{23}$ A cada 1000 fs $(1,0$ ps), a flutuação molecular obtida foi salva em arquivo a parte, formatado, contendo as coordenadas atômicas atualizadas. Foram assim coletadas 1000 combinações diferentes de coordenadas atômicas (1000 frames). O método adotado para o controle da temperatura foi o Andersen, estabelecendo por frequência de colisão uma (1) para cada trinta e cinco (35) passos. Descartado o tempo de termalização do sistema, a coleção de dados foi analisada, selecionando-se conformações representativas dentro do espaço de fase das moléculas. Em média, vinte conformações foram selecionadas a partir dos resultados provenientes das trajetórias dinâmicas. Estas foram energeticamente minimizadas através do emprego do algoritmo matemático Conjugate Gradient, com convergência a 1,0 × $10^{-4} \mathrm{kcal}$ $\mathrm{mol}^{-1}$.

Para os cálculos QSE utilizou-se o programa $A M 1,{ }^{11}$ implementado na cadeia de programas $\mathrm{VAMP},{ }^{24}$ através do Hamiltoniano $\mathrm{NDDO}^{10}$ com multiplicidade a ser automaticamente determinada pelo programa spin $\mathrm{RHF}^{25}$ e convergência até 0,1 kcal mol ${ }^{-1} \AA^{-1}$. Um máximo de 200 ciclos para o método do campo autoconsistente (self consistent Field, SCF $)^{26}$ foi estabelecido para cada cálculo, adotando o "standard converger" e uma tolerância para a convergência de $5,0 \times 10^{-7} \mathrm{eV}$ átomo ${ }^{-1}$. Para cada geometria energeticamente otimizada foram previstos os modos vibracionais (IV/Raman). ${ }^{27}$ A mesma rotina foi adotada quando do emprego dos métodos $P M 3^{5}$ e $\mathrm{PM6}^{12}$ (Figura 2).

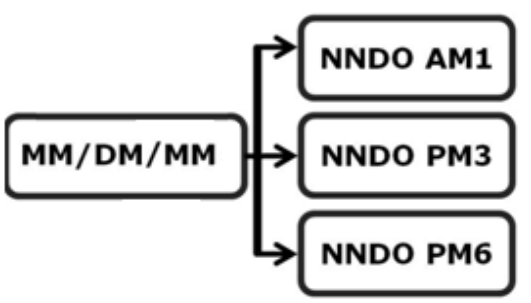

Figura 2. Esquema da metodologia adotada 


\section{Resultados e discussão}

\subsection{Resultados preliminares}

A metodologia adotada quanto aos estudos da variabilidade conformacional e de suas energias por MM/DM conduziu à adequada varredura do espaço conformacional das moléculas. Assim, por exemplo, para moléculas de maior flexibilidade (1-5,14-16), foi possível obter até oito conformações representativas, enquanto para moléculas mais rígidas (6-13) foram coletadas até quatro conformações energética e espacialmente diferentes (Figura $3)$.
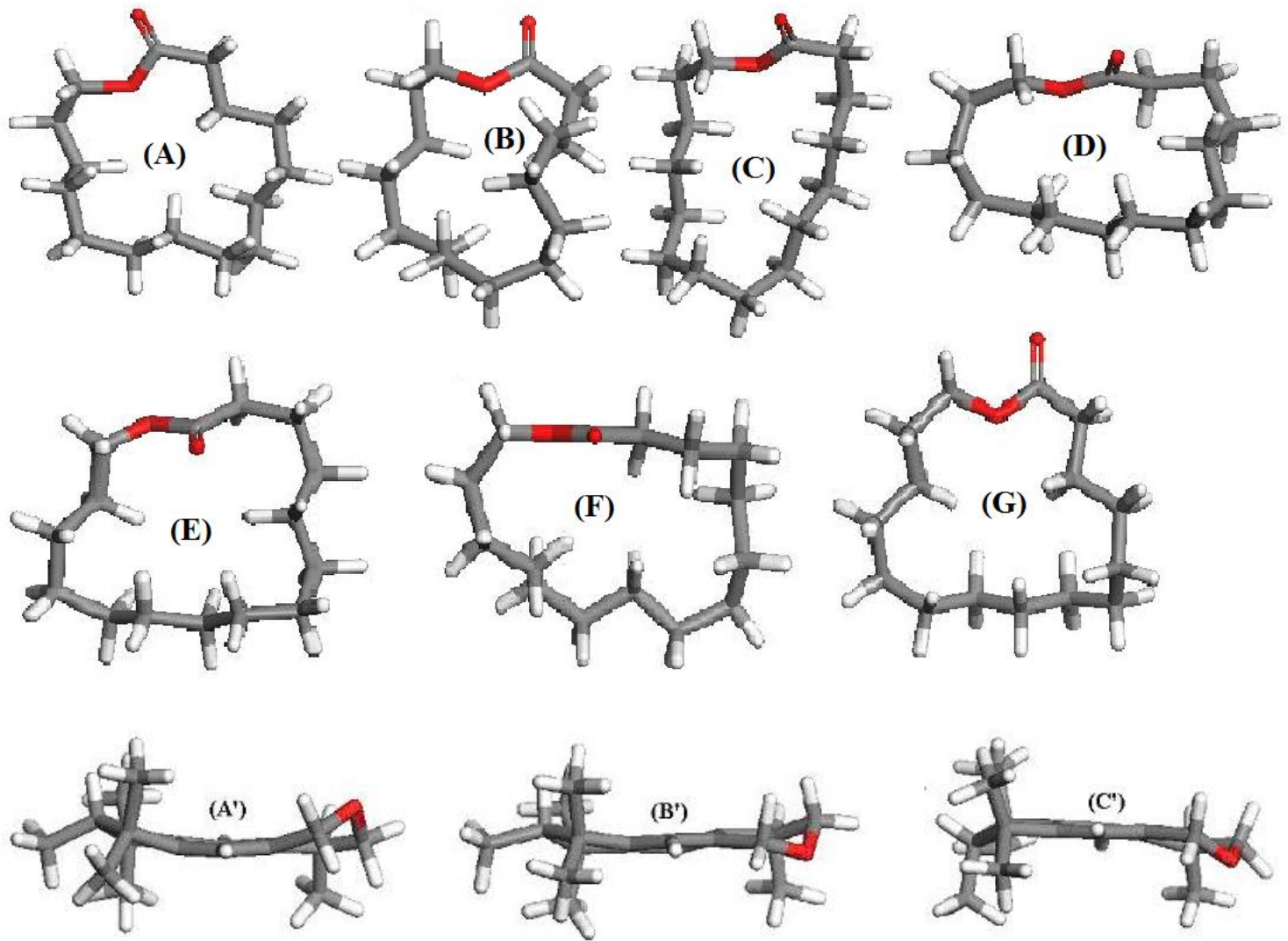

Figura 3. Seis confôrmeros dentre as conformações geradas por DM para o (R)-exaltolídeo (de A a G, composto 2) e três para o (4S,7R)-galaxolídeo (de $A^{\prime}$ a $C^{\prime}$, composto 7) ilustram a flexibilidade de um macrociclo de 16 membros e a rigidez de um triciclo

Todos os confôrmeros triados nas trajetórias dinâmicas e energeticamente reotimizados pelo campo de força ab initio Condensed-phase Optimized Mol. Potentials for Atomistic Simulation Studies (Compass), ${ }^{28}$ para cada composto sob estudo, foram submetidos à reotimização energética pelos cálculos quânticos semi-empíricos $\mathrm{AM} 1,{ }^{11}$ $\mathrm{PM} 3^{5}$ e PM6. ${ }^{12}$ A Figura 4 compila os menores calores de formação observados para cada uma das moléculas, em função do método adotado. 


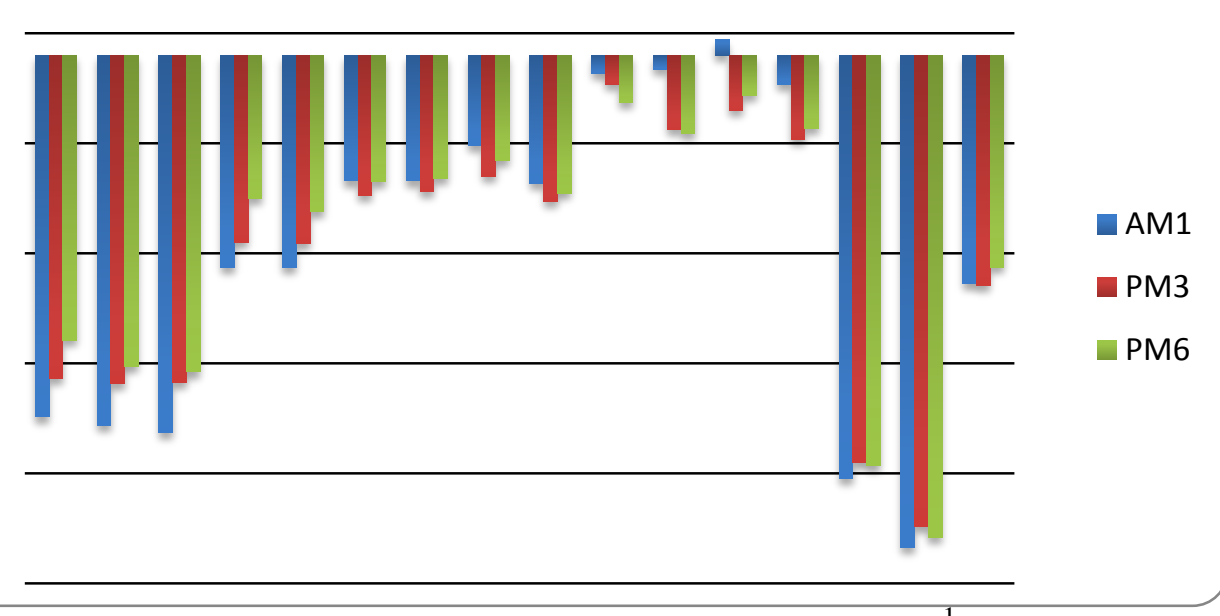

Figura 4. Comparação entre os calores de formação (em kcal.mol ${ }^{-1}$ ) para os almíscares 1-16, segundo cada método QSE

A apresentação dos dados de calor de formação se fundamenta no fato de que estes três métodos QSE foram parametrizados para reproduzir tal propriedade experimental (como comprovado na Tabela 1, que evidencia a redução dos erros médios relativos ao $\left.\Delta \mathrm{H}_{\mathrm{f}}\right) .{ }^{12}$ Não há na literatura os valores experimentais de $\Delta \mathrm{H}_{\mathrm{f}}$, por estarem os almíscares devidamente patenteados; mas há uma manutenção no comportamento da previsão desta grandeza dentro de cada classe. Assim, os macrocíclicos 1-5 têm valores menores de calores de formação por $\mathrm{AM} 1{ }^{11}$ seguido pela previsão de $\mathrm{PM}^{5}$ e de $\mathrm{PM6}^{5}{ }^{12}$ Já os nitrocompostos 11-13 têm valores decrescentes para $\mathrm{AM} 1,{ }^{11} \mathrm{PM}^{12}$ e $\mathrm{PM} 3{ }^{5}{ }^{5}$ nesta ordem. Esta coerência interna é um bom indicativo da qualidade dos cálculos realizados. A literatura traz ainda outros erros previstos para cada um dos métodos. Sublinha-se o erro associado à previsão dos momentos de dipolo intrínseco, por este relacionar-se diretamente com a espectroscopia no IV. Como somente os modos vibracionais que engendrarem uma mudança no momento de dipolo terão as transições observadas, a acurácia dos espectros dependerá também da acurácia na descrição destes momentos de dipolo efetivos. Os erros aqui associados a cada método são muito próximos, e não justificariam as diferenças observadas entre os espectros teóricos. Contudo, a associação da inacurácia desta grandeza somada às dos comprimentos e ângulos de ligação explica, na sua causa última, as discrepâncias nos espectros teóricos segundo cada método- e a necessidade de se analisar cada um individualmente.

Tabela 1. Comparação dos erros médios estabelecidos por AM1, PM3 e PM6*

Propriedade

\begin{tabular}{c|ccc|}
\hline$\Delta \mathrm{H}_{\mathrm{f}}\left(\mathrm{kcal}_{\text {.mol }}{ }^{-1}\right.$ ) & 12,57 & 8,05 & 5,05 \\
Comprimentos de ligação (Å) & 0,046 & 0,037 & 0,031 \\
Ângulos (graus) & 3,4 & 3,8 & 3,2 \\
Momentos de dipolo (Debye) & 0,38 & 0,36 & 0,37 \\
\hline
\end{tabular}




\subsection{Espectros teóricos}

A Figura 5 a seguir traz sobrepostos os espectros teóricos obtidos pelos métodos adotados, para cada um dos almíscares modelados. Deseja-se evidenciar a nítida diferença quanto à precisão na previsão dos modos vibracionais segundo os métodos quânticos semi-empíricos utilizados, sem, contudo, almejar a perfeita concordância entre dados teóricos e experimentais. Neste aspecto, a comparação direta seria bastante limitada: dos dezesseis compostos, somente sete têm seus espectros experimentais na região do IV disponíveis na literatura. São eles o pentadecanolídeo (1), ${ }^{29}$ uma mistura racêmica dos (R)-exaltolídeo (2) e (S)exaltolídeo (3), outro racemato de cisglobanona (4) e trans-globanona (5), ${ }^{30}$ o policíclico indano $(\mathbf{8})^{31}$ e nitro-almíscar mosqueno (12). ${ }^{29}$ Estes foram apresentados sequencialmente na Figura 5. Outro desafio à devida comparação entre os espectros reside no fato de que os espectros teóricos geram linhas espectrais, enquanto os experimentais fornecem bandas. A nível experimental, as bandas podem ser tanto moduladas em função do tempo corrido na coleta, como em suas intensidades. Todavia, os dados teóricos são exatos e discretos, e no programa Discover 3.0 não há recurso que permita a manipulação dos dados. Contudo, da análise dos modos vibracionais que, neste exercício comparativo, são diagnósticos, pode-se discutir a acurácia dos espectros teóricos. Os estiramentos $\mathrm{C}=\mathrm{O}$ de carbonilas e acilas são um bom exemplo: em média, por $\mathrm{AM}^{11}$ tais modos constam a $+400 \mathrm{~cm}^{-1}$ da região em que experimentalmente ocorrem (1705-1750 $\left.\mathrm{cm}^{-1}\right) ;{ }^{32}$ por $\mathrm{PM}^{5}$ ficaram previstos em +200 $\mathrm{cm}^{-1} ;$ e por $\mathrm{PM6}^{12}$ apareceram superestimados em aproximadamente $50 \mathrm{~cm}^{-}$ ${ }^{1}$. Logo, ainda que estes modos não alcancem a adequada previsão teórica, há uma grande melhoria na mesma. Dentre os três métodos adotados, sublinha-se que por $\mathrm{PM}^{5}$ os estiramentos $\mathrm{Csp}^{3}-\mathrm{H}$ foram adequadamente previstos, como também o foram as deformações $\mathrm{C}-\mathrm{H}$, estiramentos $\mathrm{C}-\mathrm{C}$ e $\mathrm{C}=\mathrm{C}$ até $1500 \mathrm{~cm}^{-1}$ por PM6. ${ }^{12}$ No entanto, os modos antissimétricos foram previstos a frequências inferiores aos modos simétricos.
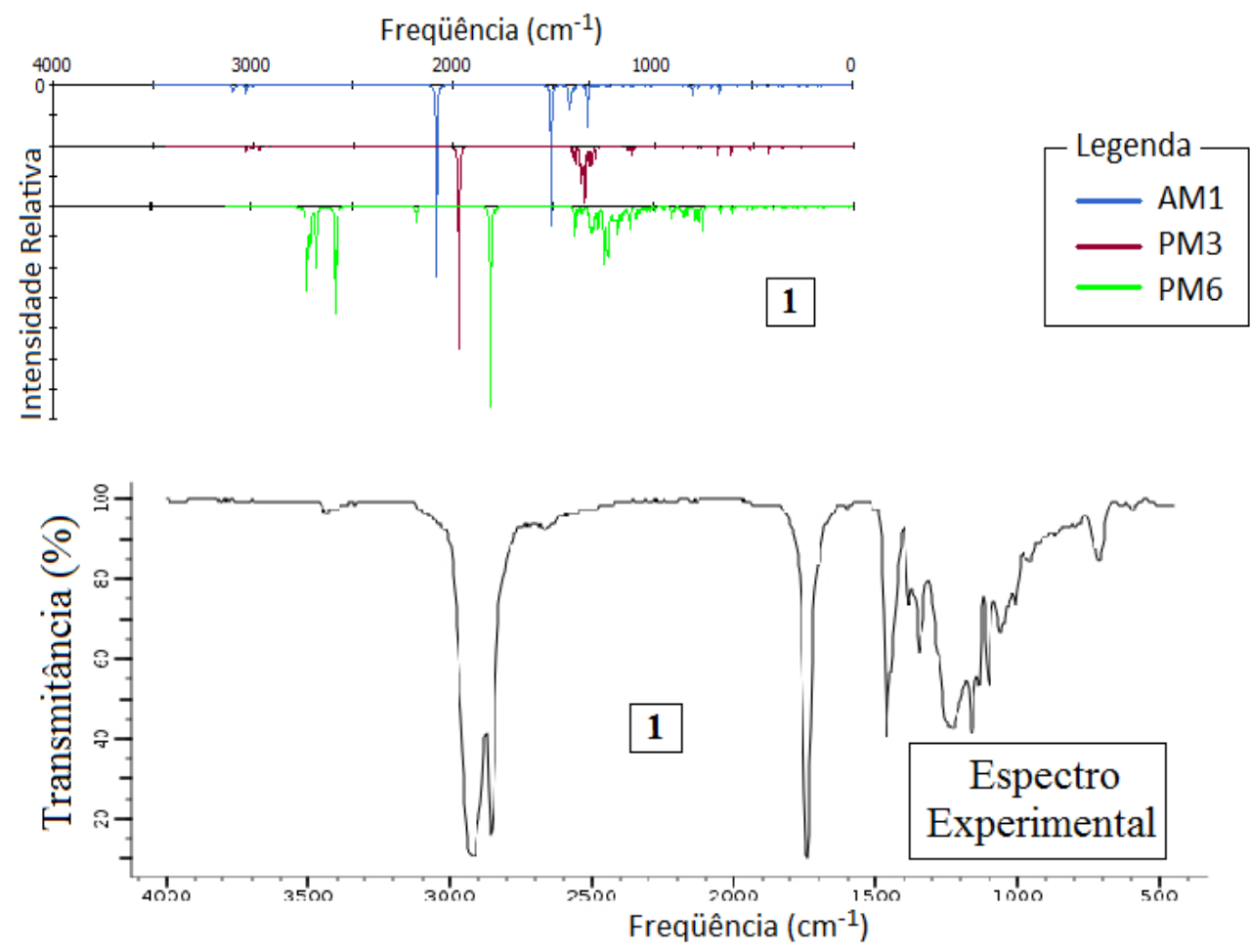

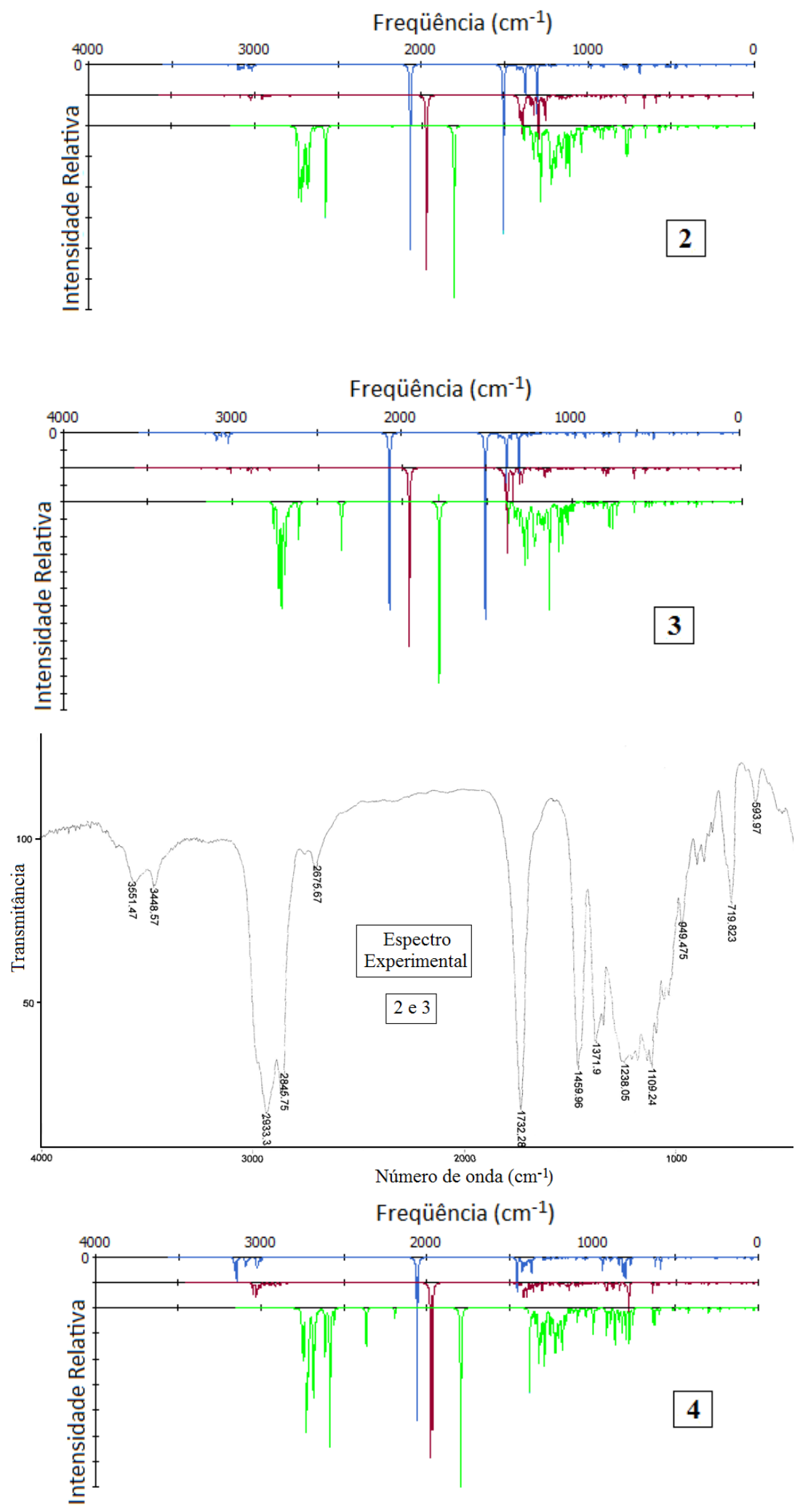
Magalhães, D. R. B.; Maia, E. R.
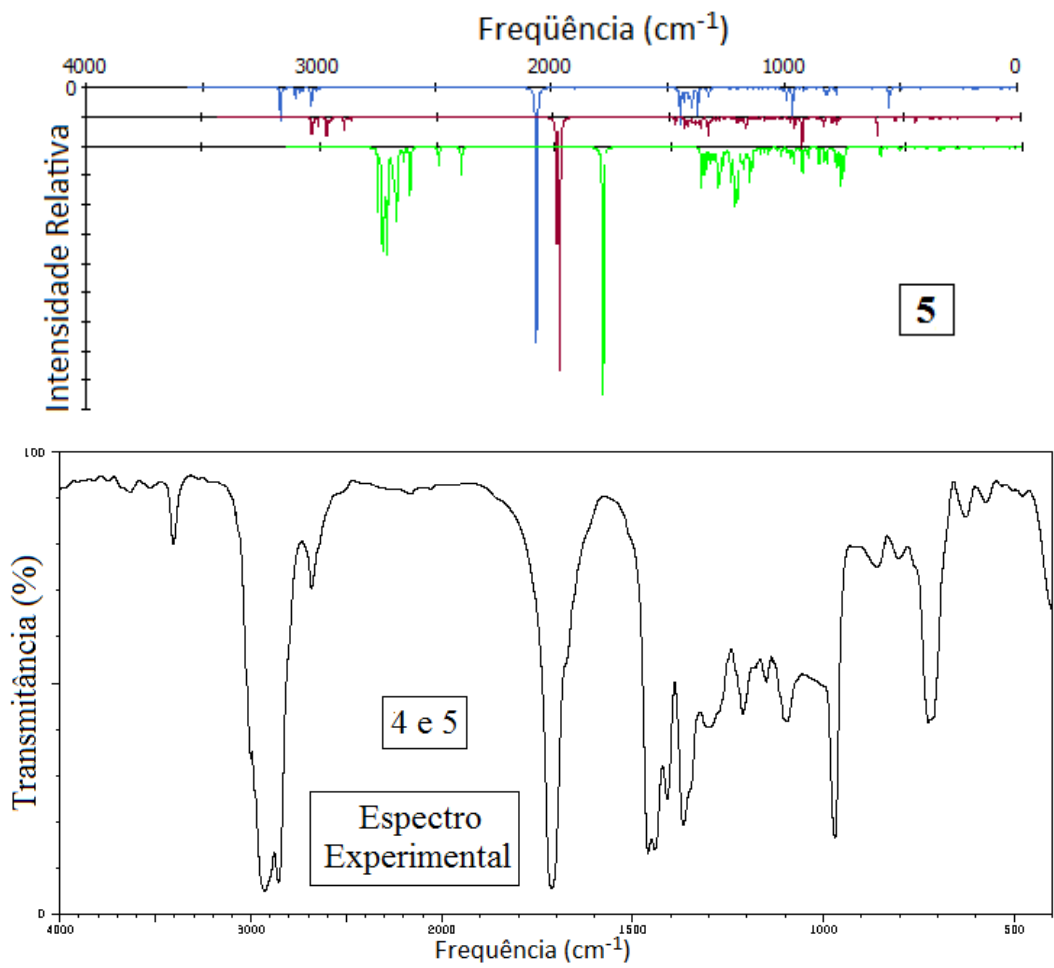

Freqüência $\left(\mathrm{cm}^{-1}\right)$

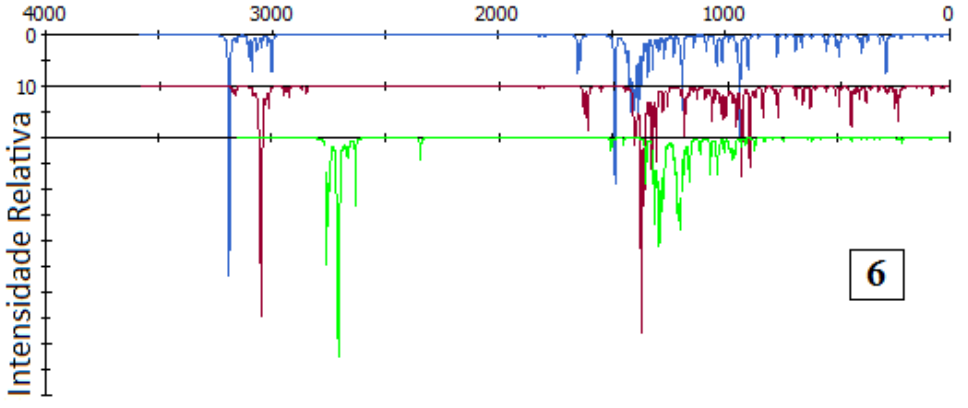

Freqüência $\left(\mathrm{cm}^{-1}\right)$

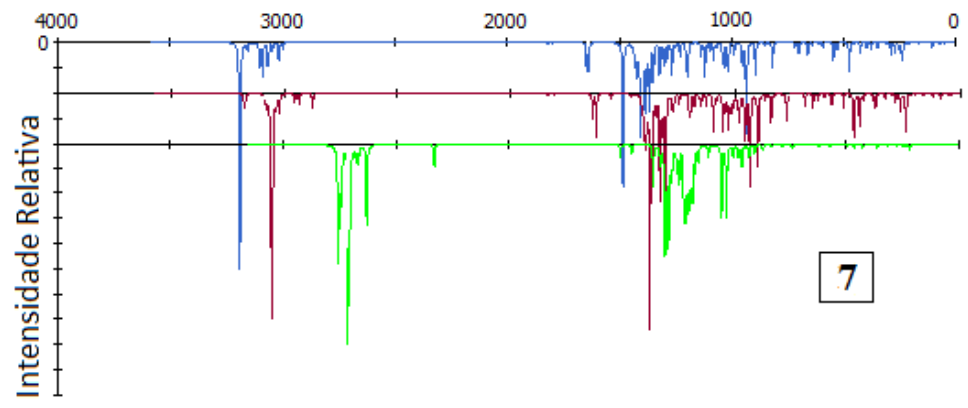



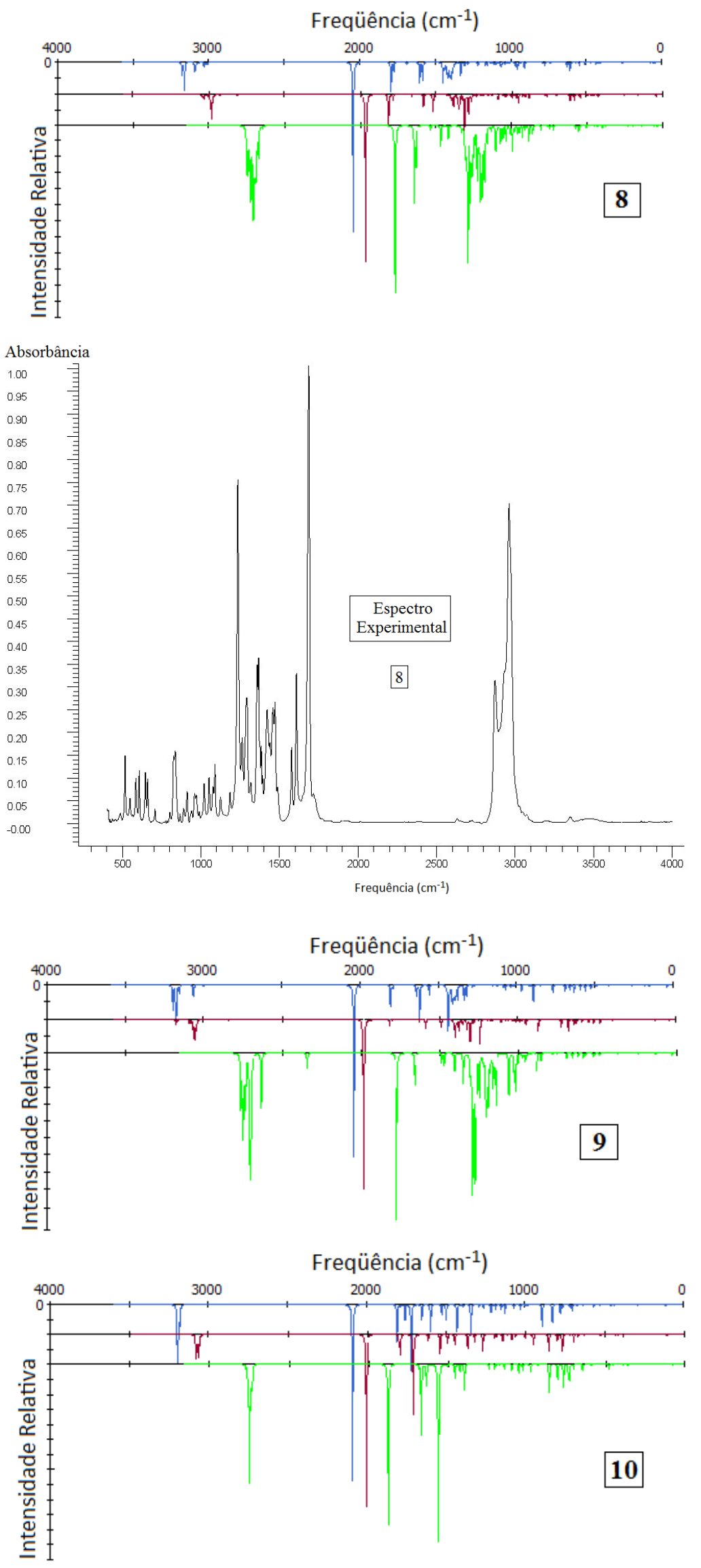
Magalhães, D. R. B.; Maia, E. R.
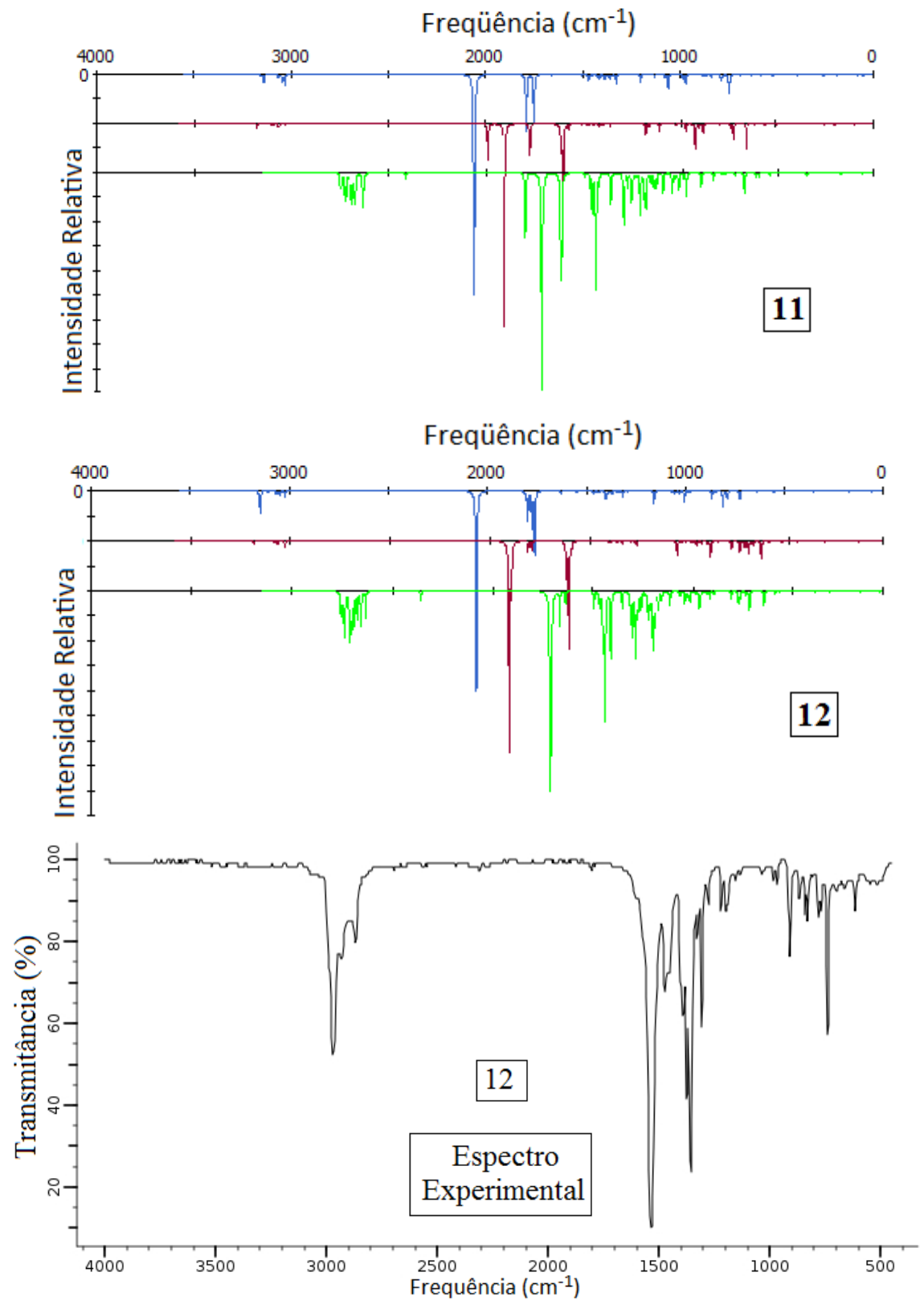

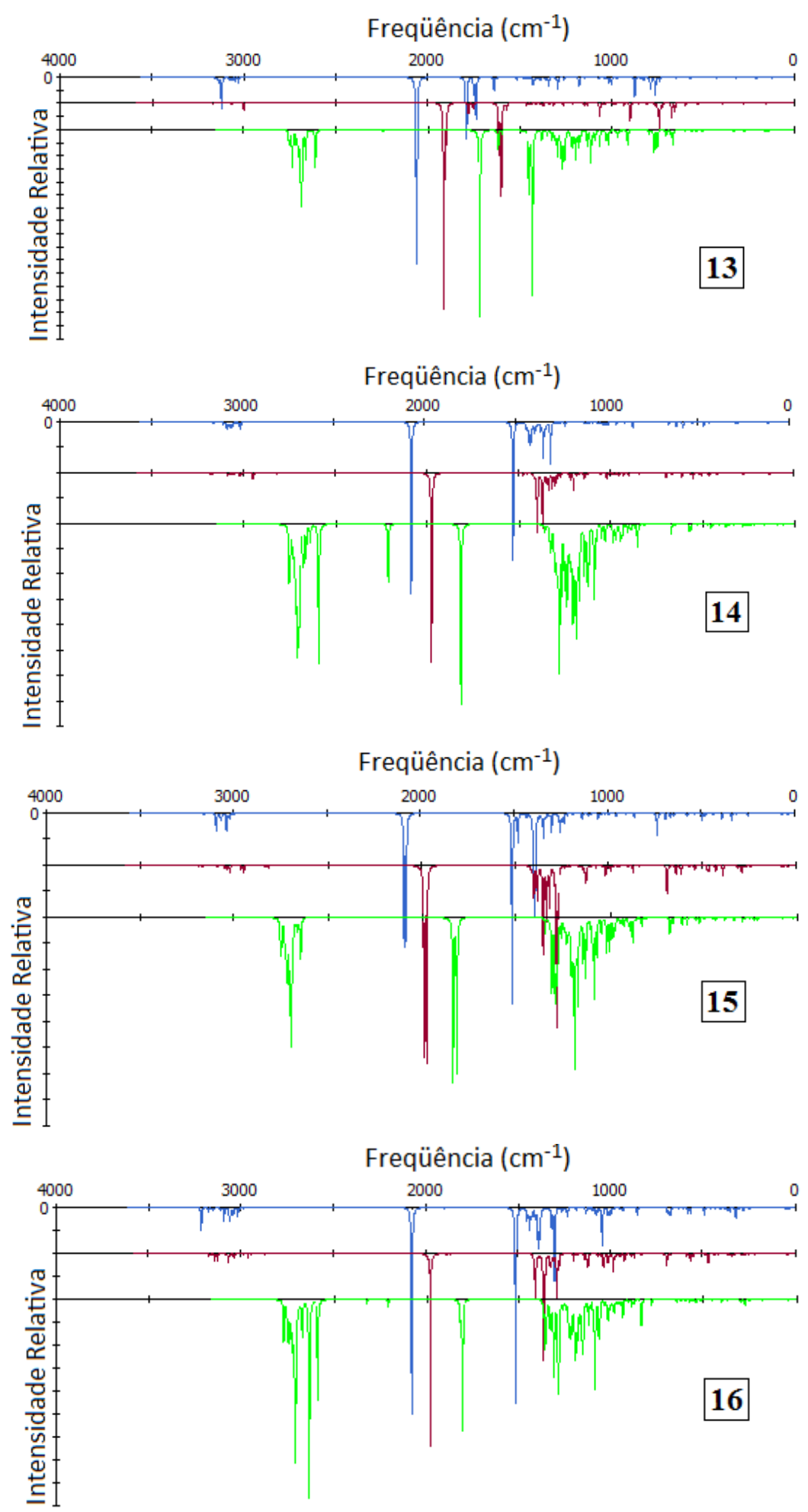

Figura 5. Espectros teóricos gerados por AM1 (linha azul), PM3 (linha vinho) e PM6 (linha verde) para os almíscares 1-16 


\subsection{Comparação com os espectros gerados por CHYPRE ${ }^{2}$}

Ainda que os métodos QSE prevejam corretamente alguns dos modos vibracionais no espectro de IV, os dados reunidos são capazes de explicar aqueles apresentados (mas não esmiuçados) no emprego do algoritmo CHYPRE. ${ }^{2}$ Este algoritmo, como já mencionado, associa exclusivamente métodos QSE $\left(\mathrm{MNDO}^{4} / \mathrm{PM}^{5}\right.$ e $\left.\mathrm{ZIndo} / 1^{6}\right)$ a outras teorias importadas da espectroscopia IETS, $^{8}$ como, por exemplo, ao que é hoje divulgado (ou talvez conhecido) sobre o reconhecimento do odor, em nível biológico.

Primeiramente, o modo esperado em $2200 \pm 200 \mathrm{~cm}^{-1}$ fora assinalado como sendo um estiramento de carbonila. Contudo, tal modo jamais ocorrerá a esta frequência. Somente estiramentos de nitrilas e alquilnitrilas podem ocorrer próximos a esta frequência, e estes grupos funcionais não constam dentre os odorantes modelados por CHYPRE. ${ }^{2}$ Neste contexto o método $A M 1^{11}$ se destaca como sendo capaz de reproduzir os estiramentos $\mathrm{C}=\mathrm{O}$ de aldeídos, cetonas $\mathrm{e}$ ésteres dentro da mencionada região do espectro (Tabela 1 e Figura 5). Os estiramentos simétricos do grupo nitro também são previstos nesta região, o que confere aos compostos 12 e 13 um pico intenso próximo a $2200 \mathrm{~cm}^{-1}$, ainda que careçam de qualquer grupo acila ou alquila. Observe-se que os almíscares 6 e 7, que não apresentam quaisquer destes grupos funcionais, não expressam nenhum modo vibracional nesta região do espectro e, contudo, são almiscarados.

Há uma segunda região no espectro, assinalada pela teoria vibracional como própria aos almíscares, em $1750 \pm 200 \mathrm{~cm}^{-1}$, para nitro-almíscares, ou em $1500 \pm 200 \mathrm{~cm}^{-1}$, para macrociclos, policíclicos e acíclicos. Nos espectros gerados por $\mathrm{AM}^{11}$ e por $\mathrm{PM}^{5}$ observa-se que tanto os nitro-almíscares quanto os policíclicos têm alguns picos, de moderada intensidade, próximos aos 1750 $\mathrm{cm}^{-1}$ : estes correspondem aos estiramentos das ligações duplas de carbonos aromáticos.
Os dados gerados por PM6, ${ }^{12}$ por outro lado, fazem coincidir os estiramentos de carbonila, acila e de grupos nitro nesta região. Não houve método QSE que gerasse um espectro particularmente diferente para os nitrocompostos, quando em comparação aos demais almíscares, nesta região do espectro. No tocante aos modos presentes em $1500 \pm$ $200 \mathrm{~cm}^{-1}$, por AM1, ${ }^{11}$ estes correspondem às deformações do tipo tesoura de grupos metil e metilenos. De fato, tais modos têm alta ou moderada intensidade para a maioria dos compostos, e aparecem com intensidades muito baixas para os nitro-almíscares, que possuem os grupos metil e metileno em menor quantidade. Já por $\mathrm{PM}^{5}$ são encontradas os mesmos modos anteriormente citados, e alguns estiramentos assimétricos do grupo nitro, dentre os almíscares 11-13. Por fim, por $\mathrm{PM6}^{12}$ os estiramentos $\mathrm{C}=\mathrm{C}_{\text {aromáticos }}$ são computados a frequências um pouco inferiores a $1500 \mathrm{~cm}^{-1}$, enquanto os estiramentos simétricos do grupo nitro constam a frequências um pouco superiores à nominada. Assim, nem os almíscares macrocíclicos nem os acíclicos têm quaisquer modos previstos na região de 1500 $\pm 200 \mathrm{~cm}^{-1}$, pelo método PM6. ${ }^{12}$

A terceira e última região demarcada no espectro como particular aos almíscares corresponde à faixa de $700 \pm 200 \mathrm{~cm}^{-1}$, com um ombro centrado em $1000 \mathrm{~cm}^{-1}$. Nenhum, dentre esses três métodos QSE, foi capaz de reproduzir, com notória intensidade, os modos nesta região, como o fez o algoritmo CHYPRE; ${ }^{2}$ mas todos os espectros teóricos trazem, a partir dos $500 \mathrm{~cm}^{-1}$, deformações e estiramentos de alcanos. Mais especificamente, os modos que ocorrem a frequências mais baixas são deformações simétricas do tipo rocking envolvendo a maioria dos átomos na cadeia carbônica; a partir dos $900 \mathrm{~cm}^{-1}$ também são observadas torções angulares entre os carbonos; deformações assimétricas do tipo rocking ocorrem entre 1000 e $1100 \mathrm{~cm}^{-1}$; e entre 1100 e $1200 \mathrm{~cm}^{-1}$ ambas as deformações do tipo wagging dos grupos $\mathrm{CH}_{2}$ e $\mathrm{CH}_{3}$ são visualizadas, bem como os estiramentos carbono-carbono. Estas informações elucidam que, na região de $500-1200 \mathrm{~cm}^{-1}$, os 
modos vibracionais envolvem a maioria dos átomos da molécula em suas deformações, enquanto os poucos estiramentos que são contabilizados se referem às ligações carbono-carbono, e são encontrados nas maiores frequências dentro deste intervalo.

\section{Conclusão}

A adoção dos métodos de MM e DM permitiu a adequada exploração da hipersuperfície de energia potencial, superando as barreiras torcionais dos primeiros confôrmeros modelados para cada um dos 16 compostos que compuseram a base de dados sob análise, de forma a garantir as devidas varreduras de seus espaços conformacionais. Tal garantia é essencial, uma vez que os almíscares macrocíciclos e os acíclicos são bastante flexíveis, e a precisão dos espectros teóricos se faz depender, em grande parte, de quão próxima esteja a geometria sob análise daquela de seu estado fundamental.

Nenhum método QSE foi capaz de reproduzir satisfatoriamente todo o espectro de IV, fato já constatado na literatura. ${ }^{33}$ Como os espectros gerados por $\mathrm{CHYPRE}^{2}$ também não coincidem com os experimentais, pois se fundamentam em métodos QSE, os dados aqui coletados tornam-se a explicar aqueles coletados por CHYPRE. ${ }^{2}$ Portanto, dos modos vibracionais observados e obtidos segundo a metodologia descrita nesse trabalho, pode-se afirmar que:

- somente por $\mathrm{AM}^{11}$ há a reprodução de uma banda em $2200 \pm 200 \mathrm{~cm}^{-1}$, que se refere tanto aos estiramentos de carbonilas e acilas quanto aos estiramentos simétricos do grupo nitro;

- estes mesmos modos são encontrados por $\mathrm{PM} 6,{ }^{12}$ próximo à banda de $1750 \mathrm{~cm}^{-1}$ assinalada para os nitro-almíscares. $\mathrm{AM} 1^{11} \mathrm{e}$ $\mathrm{PM}^{5}$ descrevem nessa região os estiramentos do anel benzênico;

- em $1500 \mathrm{~cm}^{-1}$ são previstas as deformações do tipo tesoura de grupos metil e metilenos por $\mathrm{AM} 1,{ }^{11}$ aos quais se somam os estiramentos simétricos do grupo nitro por PM3. ${ }^{5}$ Por $\mathrm{PM}^{12}$ ficam calculados tanto os estiramentos $\mathrm{C}=\mathrm{C}_{\text {aromáticos }}$ quanto os simétricos do grupo nitro;

- em toda a região de 500 a $1200 \mathrm{~cm}^{-1}$ são detectadas diferentes deformações vibracionais, que se reproduzem ao longo de toda a molécula, sem a contribuição específica de algum outro grupo funcional.

Tal panorama permite concluir que a presença de grupos acila, carbonila e nitro contribuem para a determinação do odor almiscarado, embora não sejam indispensáveis. A seguir se destacam os estiramentos das ligações de carbonos aromáticos, comuns aos almíscares policíclicos e nitro-almíscares, como possíveis participantes no mecanismo de reconhecimento da fragrância almiscarada. Por fim há uma extensa região do espectro que assinala uma sequencia de deformações de alcanos, em modos vibracionais que demandam a participação da maioria dos átomos das moléculas. Concomitantemente se observa a necessidade de muitos grupos metil e metilenos na geração de uma banda intensa, referente a deformações do tipo tesoura. Estas observações reforçam o conceito estrutural de que os almíscares devem ter longa cadeia carbônica, com poucos grupos funcionais, além de serem os voláteis de maior massa molecular. ${ }^{34}$ Todas as anotações aqui feitas também concordam com um estudo recente, que propôs que uma das condições para a percepção do odor almiscarado é (i) ou a abundância de grupos $\mathrm{CH}_{2}$ (ii) ou a presença de alguns grupos nitro. ${ }^{35}$ Estes dois últimos estudos citados, por terem sido conduzidos de forma tão diversa ao presente artigo, dão maior fidedignidade às conclusões propostas.

O estabelecimento de tais observações pode contribuir para a elucidação da relação estrutura-odor, tão importante na orientação da modelagem de novos almíscares, e para a 
identificação de compostos naturais com potencial atividade almiscarada.

\section{Agradecimentos}

Os autores agradecem à professora I. S. Resck (IQ-UnB) pelo suporte inicial ao projeto, bem como a D. Berthomieu e D. A. Lerner (ENSCM-Montpellier, França) pelo apoio à pesquisa. Agradecem, também, à Capes pelo apoio financeiro.

\section{Referências Bibliográficas}

${ }^{1}$ Laschuk, E. F.; Tese de Doutorado, Universidade Federal do Rio Grande do Sul, 2005. [Link]

${ }^{2}$ Turin, L.; A Spectroscopic Mechanism for Primary Olfactory Reception. Chemical Senses 1996, 21, 773. [CrossRef] [PubMed]

${ }^{3}$ Stewart, J. J. P., Computational Chemistry, Colorado Springs, CO, USA, MOPAC2009. Disponível em: < http://openmopac.net/>. Acesso em: 05 dezembro 2013.

${ }^{4}$ Dewar, M. J. S.; Thiel, W. Ground states of molecules. 38. The MNDO method. Approximations and parameters. Journal of the American Chemical Society 1977, 99, 4899. [CrossRef]

${ }^{5}$ a) Stewart, J. J. P. Optimization of parameters for semiempirical methods I. Method.Journal of Computational Chemistry 1989, 10, 209; [CrossRef] b) Stewart, J. J. P. Optimization of parameters for semiempirical methods II. Applications. Journal of Computational Chemistry 1989, 10, 221. [CrossRef]

${ }^{6}$ a) Ridley, J. E.; Zerner, M. C. An Intermediate Neglect of Differential Overlap Technique for Spectroscopy: Pyrrole and the Azines. Theoretica Chimica Acta 1973, 32, 111; [CrossRef] b) Ridley, J. E.; Zerner, M. C. Triplet states via Intermediate Neglect of
Differential Overlap: Benzene, Pyridine, and Diazines. Theoretica Chimica Acta 1976, 42, 223. [CrossRef]

${ }^{7}$ Sítio da Computer-Aided Chemistry \& Biochemistry Research. Disponível em: <http://www.cacheresearch.com/home.ht $\mathrm{ml}>$. Acesso em: 05 dezembro 2013.

${ }^{8}$ Reed, M. A. Inelastic electron tunneling spectroscopy. Materials Today 2008, 11, 46. [CrossRef]

${ }^{9}$ Turin, L. A Method for the Calculation of Odor Character from Molecular Structure. Journal of Theoretical Biology 2002, 216, 367. [CrossRef] [PubMed]

${ }^{10}$ a) Pople, J. A.; Segal, G. A. Approximate Self-Consistent Molecular Orbital Theory. II. Calculations with Complete Neglect of Differential Overlap. Journal of Chemical Physics 1965, 43, S136; [CrossRef] b) Pople, J. A.; Segal, G. A. Approximate Self-Consistent Molecular Orbital Theory. III. CNDO Results for $\mathrm{AB}_{2}$ and $\mathrm{AB}_{3}$ Systems. Journal of Chemical Physics 1966, 44, 3289; [CrossRef] c) Pople, J. A.; Santry, D. P.; Segal, G. A. Approximate Self-Consistent Molecular Orbital Theory. I. Invariant Procedures. Journal of Chemical Physics 1965, 43, S129. [CrossRef]

${ }^{11}$ Dewar, M. J. S.; Zoebisch, E. G.; Healy, E. F.; Stewart, J. J. P. Development and use of quantum mechanical molecular models. 76. AM1: A new general purpose quantum mechanical molecular model. Journal of the American Chemical Society 1985, 107, 3902. [CrossRef]

${ }^{12}$ Stewart, J. J. P. Optimization of parameters for semiempirical methods $\mathrm{V}$ : Modification of NDDO approximations and application to 70 elements. Journal of Molecular Modeling 2007, 13, 1173. [CrossRef] [PubMed]

${ }^{13}$ Sítio da Convenção sobre o Câmbio Internacional de Espécies Ameaçadas da Fauna e Flora Selvagens. Disponível em: $<$ http:// http://www.cites.org/eng/disc/text.php>. Acesso em: 17 abril 2012. 
${ }^{14}$ Yang, Q.; Meng, X.; Xia, L.; Feng, Z. Conservation status and causes of decline of musk deer (Moschus spp.) in China. Biological Conservation 2003, 109, 333. [CrossRef]

${ }^{15}$ Thomas, P. D.; Stephens Jr., C. R.; United States Patent Office 3,415,813 1968

${ }^{16}$ Zhu, T.; Cao, S.; Su, P-C.; Patel, R.; Shah, D.; Chokshi, H. B.; Szukala, R.; Johnson, M. E.; Hevener, K. E. Hit Identification and Optimization in Virtual Screening: Practical Recommendations Based on a Critical Literature Analysis. Journal of Medicinal Chemistry 2013, 56, 6560. [CrossRef] [PubMed]

${ }^{17}$ Accelrys:

Materials

Studio/Builder/Analysis/Discover/DMol3/ VAMP programs, 4.4 version. 9685 Scranton Road, San Diego, CA 921213752, USA.

${ }^{18}$ Mackay, D. H. J.; Cross, A. J.; Hagler, A. T. Em Prediction of Protein Structure and the Principles of Protein Conformation; Fasman, G. D., ed.; Plenum Press: New York, 1990, cap. 2.

${ }^{19}$ Dauber-Osguthorpe P.; Roberts, V. A.; Osguthorpe, D. J.; Wolff, J.; Genest, M.; Hagler, A. T. Structure and energetics of ligand binding to proteins: Escherichia coli dihydrofolate reductase-trimethoprim, a drug-receptor system. Proteins 1998, 34, 31. [CrossRef] [PubMed]

${ }^{20}$ Maple, J. R.; Hwang, M-J.; Stockfisch, T. P.; Dinur, U.; Waldman, M.; Ewig, C. S.; Hagler, A. T. Derivation of class II force fields. I. Methodology and quantum force field for the alkyl functional group and alkane molecules. Journal of Computational Chemistry 1994, 15, 162. [CrossRef]

${ }^{21}$ Dinur, U.; Hagler, A. T.; Em Reviews in Computational Chemistry; Lipkowitz, K. B.; Boyd, D. B. eds.; Wiley-VCH: New York, 1991, vol. 2, cap. 4.

${ }^{22}$ Cornell, W. D.; Cieplak, P.; Bayly, C. I.; Gould, I. R.; Merz, K. M.; Ferguson, D. M.; Spellmeyer, D. C.; Fox, T.; Caldwell, J. W.; Kollman, P. A. A Second
Generation Force Field for the Simulation of Proteins, Nucleic Acids, and Organic Molecules. Journal of the American Chemical Society, 1995, 117, 5179. [CrossRef]

${ }^{23}$ Español, P.; Warren, P. Statistical Mechanics of Dissipative Particle Dynamics. Europhysics Letters 1995, 30, 191. [CrossRef]

${ }^{24}$ Clark, T.; Alex, A.; Beck, B.; Burkhardt, F.; Chandrasekhar, J.; Gedeck, P.; Horn, A. H. C.; Hutter, M.; Martin, B.; Rauhut, G.; Sauer, W.; Schindler, T.; Steinke, T. VAMP 8.0; Erlangen: San Diego, 2001.

${ }^{25}$ Mayer, I. Spin-projected EHF method. IV. Comparison of potential curves given by different one-electron methods. International Journal of Quantum Chemistry 1978, 14, 29. [CrossRef]

${ }^{26}$ Szabo, A.; Ostlund, N. S.; Modern quantum chemistry: introduction to advanced electronic structure theory, Courier Dover Publications, INC: New York, 1996.

${ }^{27}$ Wilson, E. B.; Decius, J. C.; Cross, P. C. Molecular Vibrations, Dover: New York, 1955.

${ }^{28}$ Sun, H. COMPASS: An ab Initio Force-Field Optimized for CondensedPhase Applications - Overview with Details on Alkane and Benzene Compounds. Journal of Physical Chemistry B 1998, 102, 7338. [CrossRef]

${ }^{29}$ BIORAD: Infrared spectral data from the Bio-Rad/Sadtler IR Data Collection was obtained from Bio-Rad Laboratories, Philadelphia, PA (US). Copyright (C) BioRad Laboratories. All Rights Reserved. Disponível em < http://www.biorad.com/en-us/product/ir-databases $>$.

Acesso em: 03 outubro 2014.

${ }^{30}$ AIST: Integrated Spectral Database System of Organic Compounds. (Data were obtained from the National Institute of Advanced Industrial Science and Technology (Japan)). Disponível em < http://sdbs.db.aist.go.jp/sdbs/cgi- 
bin/cre_index.cgi>. Acesso em: 03 outubro 2014.

${ }^{31}$ WSS: Spectral data were obtained from Wiley Subscription Services, Inc. (US).

${ }^{32}$ Pavia, D. L.; Lampman, G. M.; Kriz, G. S.; Vyvyan, J. R.; Introduction to Spectroscopy, 5a. ed., Cegage Learning: São Paulo, 2010.

${ }^{33}$ Scott, A. P.; Radom, L. Harmonic Vibrational Frequencies: An Evaluation of Hartree-Fock, Møller-Plesset, Quadratic Configuration Interaction, Density Functional Theory, and Semiempirical Scale Factors. Journal of Physical Chemistry 1996, 100, 16502. [CrossRef]

${ }^{34}$ Eh, M. New Alicyclic Musks: The Fourth Generation of Musk Odorants. Chemistry \& Biodiversity 2004, 1, 1975. [CrossRef] [PubMed]

${ }^{35}$ Gane. S.; Georganakis, D.; Maniati, K.; Vamvakias, M.; Ragoussis, N.; Skoulakis,
E. M. C.; Turin, L. Molecular VibrationSensing Component in Human Olfaction. Plos One 2013, 8, e55780. [CrossRef] [PubMed] 